Supporting information for:

\title{
Interfacial Instability of Emulsion Droplets Containing Polymer and Fatty Alcohols
}

Shanqin Liu*, Xuanhe Li, Linfeng Hu, Shaohuan Deng, Wanqing Zhang, Pengfei Liu, Yuping

Zhang*

School of Chemistry and Chemical Engineering, Henan Institute of Science and Technology,

Xinxiang 453003, Henan, P. R. China 
Table S1. Calibration of the micropipette aspiration measurement of interfacial tension (IFT)

\begin{tabular}{ccc}
\hline Solvent & Experimental & Literature value \\
& results $(\mathrm{mN} / \mathrm{m})$ & $(\mathrm{mN} / \mathrm{m})$ \\
\hline Chloroform/water & $31.6 \pm 2.3$ & 31.6 \\
Dichloromethane/water & $29.3 \pm 1.8$ & 28.0 \\
\hline
\end{tabular}

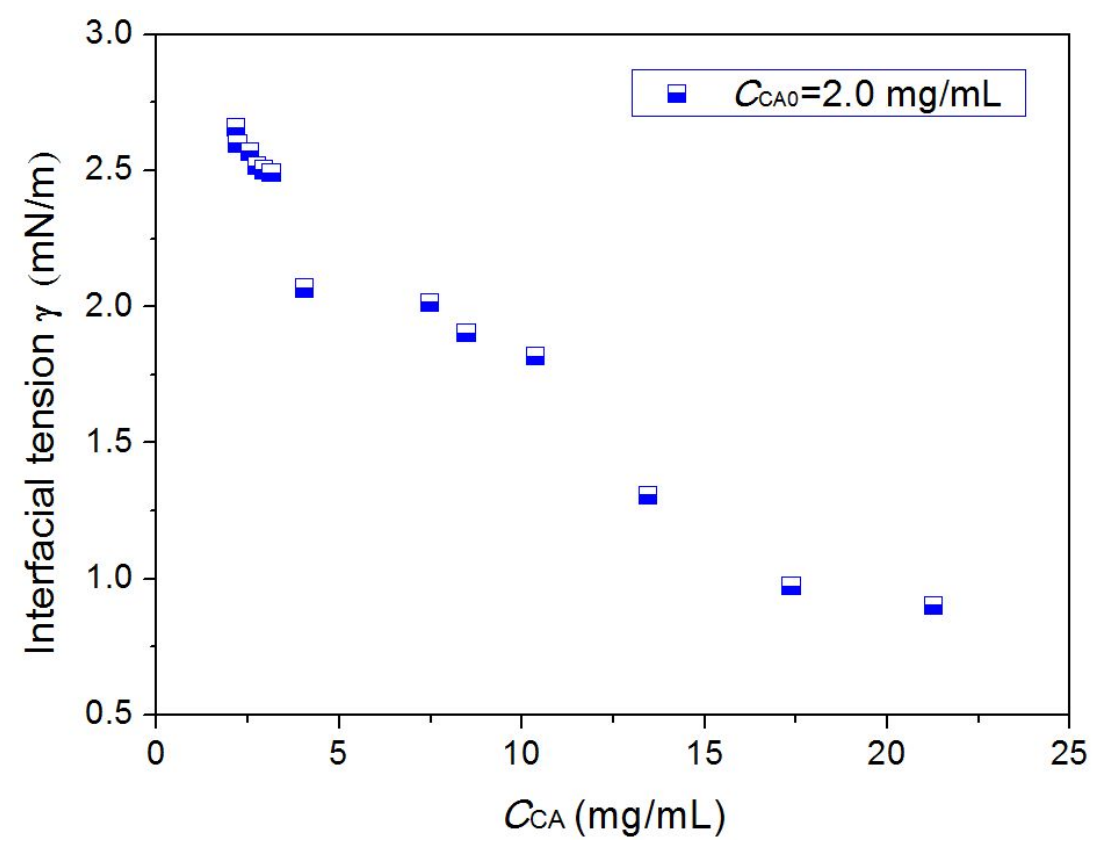

Figure S1. IFT of a droplet containing initially $2.0 \mathrm{mg} / \mathrm{mL} \mathrm{CA}$ in the absence of PS during solvent evaporation in $3.0 \mathrm{mg} / \mathrm{mL}$ SDS aqueous solution by the capillary suction method. 


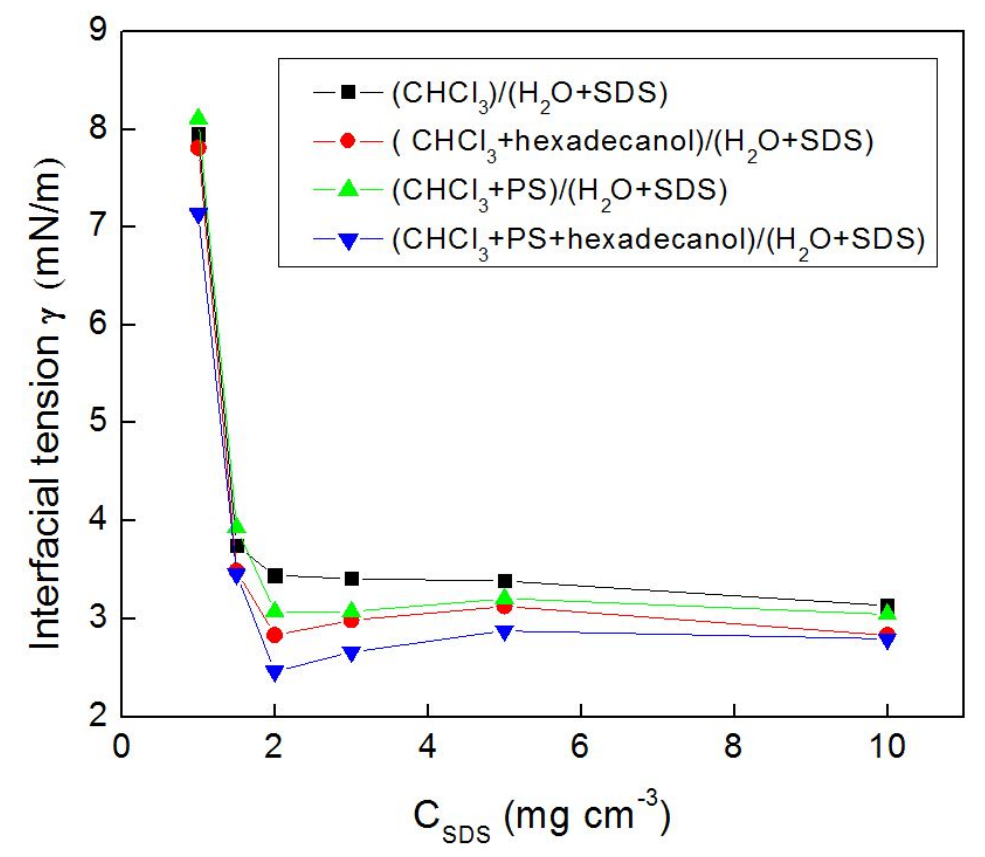

Figure S2. Static IFTs of droplets with different oil phase composition in SDS aqueous solution with varied concentration by hanging drop method.

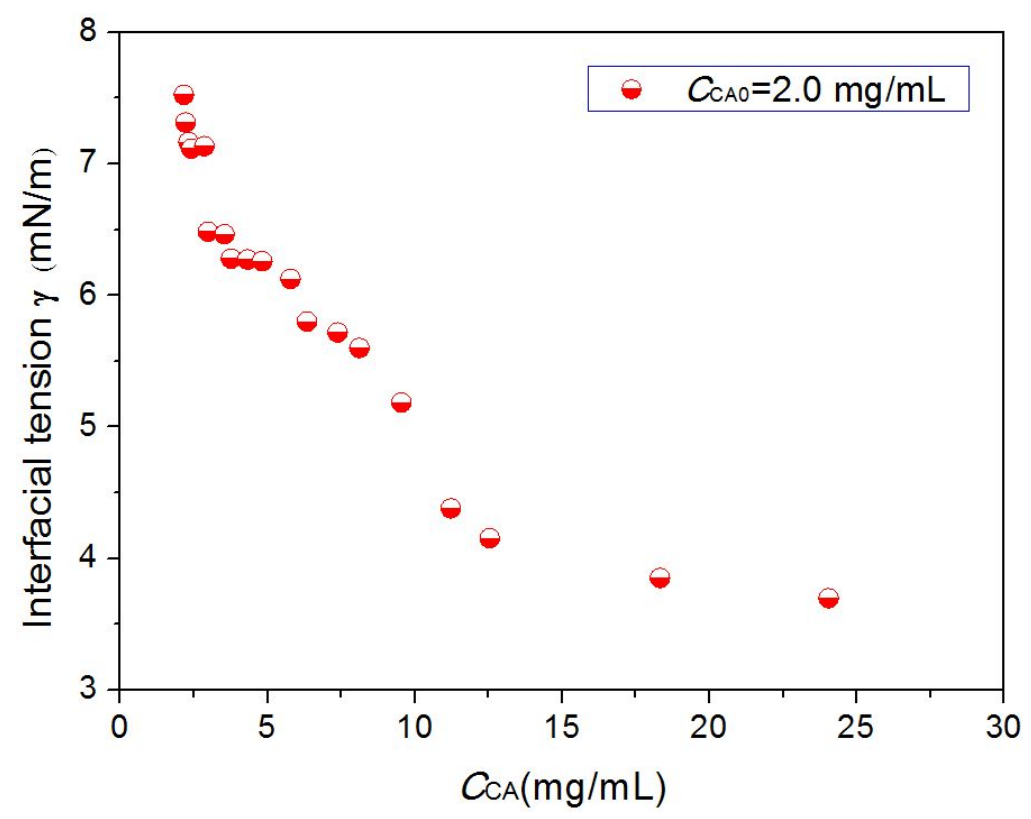

Figure S3. IFT of a droplet containing initially $10 \mathrm{mg} / \mathrm{mL}$ PS and $2.0 \mathrm{mg} / \mathrm{mL}$ CA during solvent evaporation in $0.5 \mathrm{mg} / \mathrm{mL}$ SDS aqueous solution by the capillary suction method. 


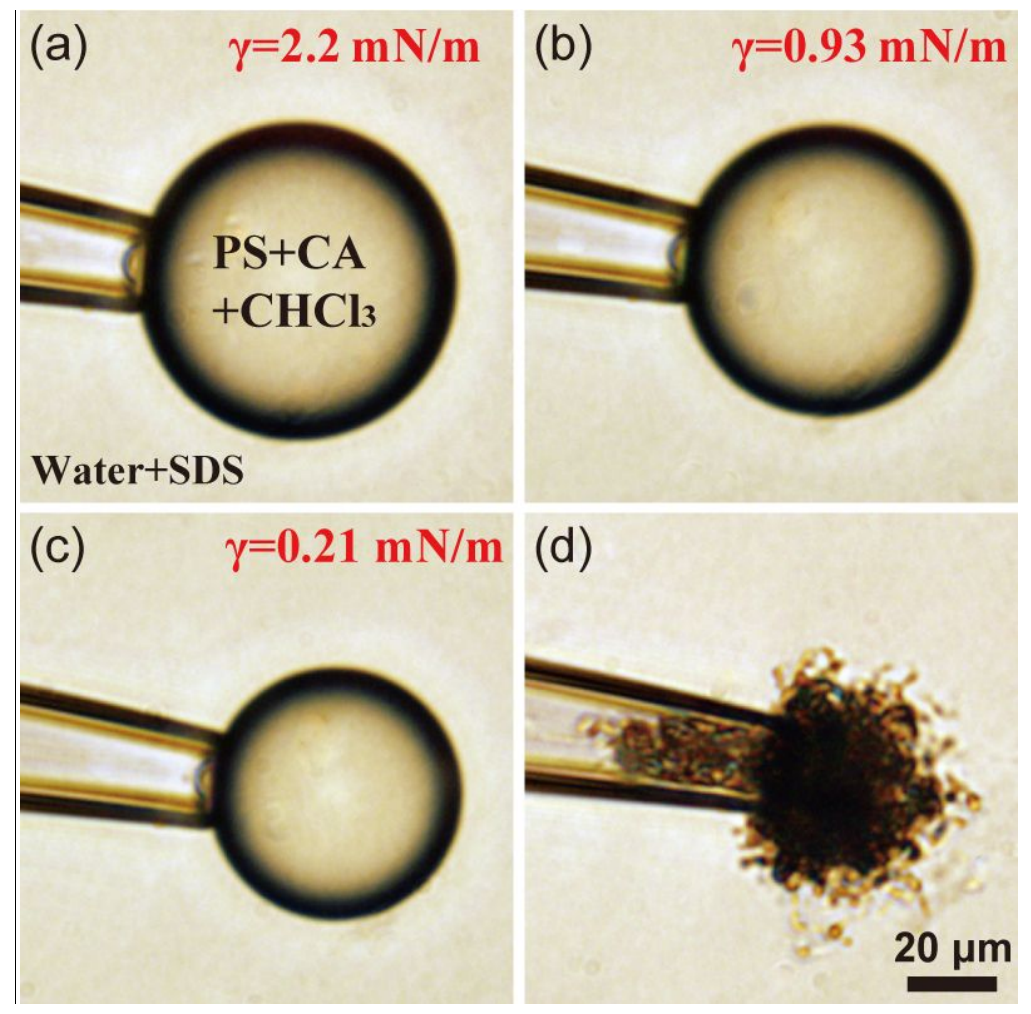

Figure S4. Optical micrographs of the evolution of a chloroform droplet initially containing $10 \mathrm{mg} / \mathrm{mL} \mathrm{PS} 21 \mathrm{k}$ and $2.0 \mathrm{mg} / \mathrm{mL}$ CA during solvent evaporation in 3.0 $\mathrm{mg} / \mathrm{mL}$ SDS aqueous solution. Scale bar in (d) applies to all. IFTs were measured by the capillary suction method. 